\title{
ЗАСТОСУВАННЯ КОРЕЛЯЦІЙНОГО ПОРТРЕТУ В ДИФЕРЕНЦІЙНІЙ ДІАГНОСТИЦІ ЗАХВОРЮВАНЬ СЕРЦЕВО-СУДИННОЇ, ЛЕГЕНЕВОЇ TA НЕРВОВОÏ СИСТЕМ
}

\author{
Д. В. Вакуленко, Л. О. Вакуленко, Н. О. Кравець, \\ О. В. Кутакова ${ }^{1}$, А. С. Сверстюк, В. В. Лесів ${ }^{2}$ \\ ДВНЗ «Тернопільський державний медичний університет \\ імені І. Я. Горбачевського МОЗ України» \\ ${ }^{1}$ Комунальна установа «Центральна районна лікарня» Житомирської районної ради \\ ${ }^{2}$ Тернопільський національний технічний університет ім. І. Пулюя
}

\begin{abstract}
Описано алгоритм побудови кореляційного портрету адаптаційних механізмів перебігу захворювань при проведенні медичних наукових досліджень. Представлено кореляційний портрет показників вимірювань артеріальних осцилограм та електрокардіограм при серцево-судинних, легеневих захворюваннях, порушеннях мозкового кровообігу, остеохондрозі шийного відділу хребта та у здорових індивідуумів.
\end{abstract}

Ключові слова: кореляційний портрет, артеріальна осцилографія, ЕКГ.

\section{APPLICATION OF CORRELATION PORTRAIT IN THE DIFFERENTIAL DIAGNOSIS OF CARDIOVASCULAR, PULMONARY AND NERVOUS DISEASES}

\section{V. Vakulenko, L. O. Vakulenko, N. O.Kravets, O. V. Kutakova ${ }^{1}$, A. S. Sverstyuk, V. V. Lesiv ${ }^{2}$}

SHEI "I. Ya. Gorbachevsky Ternopil state medical university of MH of Ukraine"

${ }^{1}$ Municipal institution "Central District Hospital» Zhytomyr District Council

${ }^{2}$ I. Pul'uj Ternopil National Technical University

\begin{abstract}
An algorithm for constructing a correlation portrait of adaptation mechanisms of disease course during medical research is described in the article. The correlation portrait of the arterial oscillograms and electrocardiograms measurements for cardiovascular, pulmonary diseases, cerebral circulation disorders, and degenerative disc disease of the cervical spine and in healthy subjects is presented.
\end{abstract}

Key words: correlation portrait, arterial oscillography, ECG. 


\title{
ПРИМЕНЕНИЕ КОРРЕЛЯЦИОННОГО ПОРТРЕТА В ДИФФЕРЕНЦИАЛЬНОЙ ДИАГНОСТИКЕ ЗАБОЛЕВАНИЙ СЕРДЕЧНО-СОСУДИСТОЙ, ЛЕГОЧНОЙ И НЕРВНОЙ СИСТЕМ
}

\author{
Д. В. Вакуленко, Л. А. Вакуленко, Н. О. Кравец, \\ А. В. Кутакова ${ }^{1}$, А. С. Сверстюк, В. В. Лесив ${ }^{2}$ \\ ГВУЗ «Тернопольский государственный медицинский университет \\ имени И. Я. Горбачевского МЗ Украины» \\ ${ }^{1}$ Коммунальное учреждение «Центральная районная больница» \\ Житомирского районного совета \\ ${ }^{2}$ Тернопольский национальный технический университет им. И. Пулюя
}

\begin{abstract}
Описан алгоритм построения корреляционного портрета адаптационных механизмов течения заболеваний при проведении медицинских исследований. Представлен корреляционный портрет показателей измерений артериальных осциллограмм и электрокардиограмм при сердечно-сосудистых, легочных заболеваниях, нарушениях мозгового кровообращения, остеохондрозе шейного отдела позвоночника и у здоровых лиц.
\end{abstract}

Ключевые слова: корреляционный портрет, артериальная осциллография, ЭКГ.

Вступ. У різних областях медицини, біології, організації охорони здоров'я, соціально-гігієнічних і клінічних дослідженнях проводиться статистичний аналіз зв'язків, вивчення закономірностей і факторів, що на них впливають. Існують два види прояву кількісних взаємозв'язків між ознаками (явищами, факторами) - функціональні і кореляційні. При функціональних залежностях кожному значенню однієї змінної величини відповідає одне цілком визначене значення іншої змінної. Такі залежності спостерігаються в математиці й фізиці. Різні вимірювальні прилади засновані на функціональній залежності, наприклад, висота ртутного стовпчика дає однозначну відповідь про температуру.

Кореляційні зв'язки - це ті, при яких зміні значення однієї змінної відповідає зміна значення іншої змінної. Досліджувані процеси можуть мати різний характер зміни, часто вони відрізняються від лінійних. Для визначення лінійного ступеня взаємозв'язку між показниками використовують метод Пірсона [4], за яким розраховують коефіцієнт кореляції. У цій роботі запропоновано підхід для оцінки лінійних взаємозв'язків між досліджуваними показниками, щодо інших - це предмет наступних досліджень.

Наприклад, при підйомі по сходах, зазвичай, достатньо скоротливої функції м'язів ніг. При втомі в похилому віці вже виникає потреба у використанні перил, милиць, тощо. Це вказує, що для виконання однієї задачі може бути задіяна різна кількість механізмів. До кожного нового явища, патологічного стану організм людини адаптується можливим для нього чином, задіюючи необхідні (можливі) для цього механізми. Саме оцінку величини та направленості показників, які змінюються у відповідь на навантаження (внутрішнє чи зовнішнє), визначає коефіцієнт кореляції. Кореляційний зв'язок визначається для всієї сукупності спостережень: виявлення взаємодії факторів [1].

Слід підкреслити, що визначення наявності зв'язку між явищами і факторами є справою фахівців. Статистика лише вимірює цей зв'язок.

При проведенні фундаментальних досліджень перебігу захворювання чи реабілітаційного процесу важливо бачити так званий кореляційний портрет. Тобто визначити вплив (участь) кожного показника у процесі адаптації. Нами розроблено алгоритм побудови кореляційного портрету на основі аналізу артеріальної осцилограми (АО) [2].

Мета дослідження: на основі існуючих підходів [2] вивчення взаємозв'язків реакцій при різних патологічних станах запропонувати підхід до побудови кореляційного портрету адаптаційних механізмів (патологічного процесу) у відповідь на внутрішній або зовнішній подразник.

Матеріали та методи дослідження. Обстежено 720 осіб чоловічої та жіночої статі віком 18-87 років, без скарг на стан здоров'я та 3 різними патологічними станами (14 нозологічних одиниць). Вимірювання проводили на кафедрі медичної інформатики Тернопільського державного медичного університету (ТДМУ) імені І. Я. Горбачевського, в санаторії-профілакторії Тернопільського національного педагогічного університету імені 
В. Гнатюка, на клінічних базах м. Тернополя та м. Житомира в 2012-2017 роках. Для порівняльного аналізу використано відкриту базу біосигналів physionet.org. Осцилограми реєстрували в стані спокою (в положенні сидячи та лежачи), на правій та лівій руці та при різних фізичних, термічних та мультимедійних впливах (28 видів).

Вимірювання артеріального тиску з подальшою реєстрацією АО проведено за допомогою електронного вимірювача тиску ВАТ41-2 на лівому та правому плечі. Формування та запис АО відбувалися в автоматичному режимі, синхронно 3 нагнітанням повітря в манжету і реєстрацією відповіді артерії на стискання протягом усього періоду компресії 3 подальшим застосуванням методів морфологічного, часового, спектрального аналізу [2]. Два останні проводились відповідно до методів, що використовують при аналізі варіабельності серцевого ритму.

Аналіз біосигналів 3 подальшим розрахунком показників та статистичним аналізом проводили за допомогою розробленого авторами програмного cepедовища «OscEcgReoPuls», в якому додатково до прийнятих методів часового та спектрального аналізу RR-інтервалів реалізовано спектральний аналіз за перетворенням Фур'є та Гільберта - Хуанга самого сигналу для АО 413 показників, а для електрокардіограми (ЕКГ) - 132. Між згрупованими за патологіями і різними навантаженнями показниками визначався коефіцієнт кореляції.

Обрані значення кореляції піддавалися кластерному аналізу (метод k-середніх) [3], де групувались розраховані значення кореляції. Кореляти групували окремо всередині одного експерименту та між усіма показниками до та після експерименту в 12 кластерів із наступними координатами центроїдів (рис. 1).

Згруповані в кластери кореляти (рис. 1) сортували за такими критеріями - складовими кореляційного портрету:

1. У проведених експериментах значення кореляцій в кластері не виходили за межі одного кластера, були нечутливі до діючих чинників.

2. В експерименті значення кластера було унікальним (специфічним) саме до певного чинника 3 усього переліку проведених експериментів.

3. При вивченні певних видів впливу вивчали спільні та унікальні кореляти на різних етапах дослідження.

4. Кількість значущих корелят до та після експерименту.

5. Кількість та вага показників в кореляційному портреті.

6. Кількість корелят з прямою та оберненою залежністю.

7. Кількість корелят 3 кожного рівня регуляції нервової системи.

8. Які рівні регуляції нервової системи корелюють та як часто (ULF, VLF, LF, HF).

9. Частота та кількість залучених в адаптаційні процеси показників частотою більше 0,4 Гц (пов'язаних із мозковою діяльністю) за перетворенням Фур'є та Гільберта - Хуанга.

10. Частота та кількість корелят показників, розрахованих за позитивними та негативними екстремумами.

\begin{tabular}{|l|r|r|}
\hline & \multicolumn{1}{|c|}{ X } & \multicolumn{1}{c|}{ Y } \\
\hline Centroid 1 & 0,9 & 0,9 \\
\hline Centroid 2 & $-0,9$ & $-0,9$ \\
\hline Centroid 3 & $-0,9$ & 0,9 \\
\hline Centroid 4 & 0,9 & $-0,9$ \\
\hline Centroid 5 & 0,7 & 0,7 \\
\hline Centroid 6 & $-0,7$ & $-0,7$ \\
\hline Centroid 7 & $-0,7$ & 0,7 \\
\hline Centroid 8 & 0,7 & $-0,7$ \\
\hline Centroid 9 & 0,3 & 0,3 \\
\hline Centroid 10 & $-0,3$ & $-0,3$ \\
\hline Centroid 11 & $-0,3$ & 0,3 \\
\hline Centroid 12 & 0,3 & $-0,3$ \\
\hline
\end{tabular}

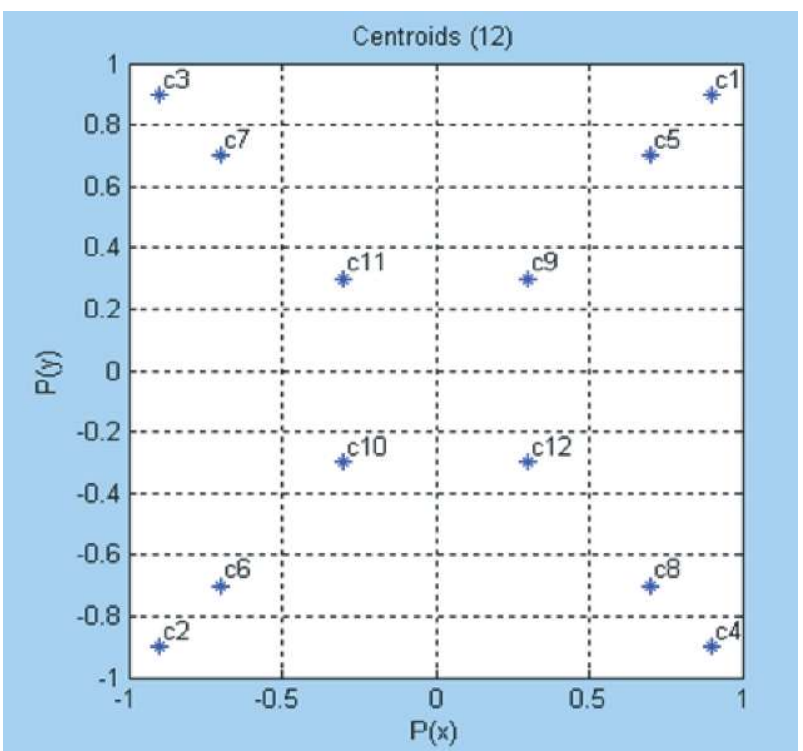

Рис. 1. Розподіл центроїдів по кластерах відповідно до методу k-середніх 
Складова кореляційного портрету деяких станів

\begin{tabular}{|c|c|c|c|c|c|c|c|c|c|}
\hline \multicolumn{2}{|l|}{ Здорові } & \multicolumn{2}{|l|}{ ШOX } & \multicolumn{2}{|c|}{$\begin{array}{c}\text { Інсульт, } \\
\text { гостра фаза }\end{array}$} & \multicolumn{2}{|c|}{ Постінсульт } & \multicolumn{2}{|l|}{ КС } \\
\hline додатні & $\mathrm{n}$ & додатні & $\mathrm{n}$ & додатні & $\mathrm{n}$ & додатні & $\mathrm{n}$ & додатні & $\mathrm{n}$ \\
\hline VLF & 3 & VLF & 3 & VLF & 3 & VLF & 3 & $\mathrm{HF}$ & 4 \\
\hline VLF-int_p & 3 & Alpha & 3 & Alpha & 3 & VLF_int_p & 3 & VLF & 3 \\
\hline IVR-pos & 2 & VLF_int_p & 3 & VLF_int_p & 3 & IVR-p & 2 & Alpha & 3 \\
\hline HVR-ind-p & 1 & IVR-p & 2 & IVR-p & 2 & HF & 2 & VLF_int_p & 3 \\
\hline HVR-ind-n & 1 & $\mathrm{HF}$ & 2 & IVR-n & 2 & HVR-ind-p & 1 & IVR-p & 2 \\
\hline SI_pos & 1 & Beta & 2 & $\mathrm{HF}$ & 2 & HVR-ind-n & 1 & $\% \mathrm{HF}$ & 2 \\
\hline L1_pos & 1 & HFx 25 & 2 & $\% \mathrm{HF}$ & 2 & SI_p & 1 & $\%$ Alpha & 2 \\
\hline Delta & 1 & $\mathrm{HFx} 25$ & 2 & $\%$ Alpha & 2 & L1_p & 1 & Beta & 2 \\
\hline Teta & 1 & HVR-p & 1 & Beta & 2 & Delta & 1 & $\%$ Beta & 2 \\
\hline Alpha & 1 & HVR-n & 1 & $\%$ Beta & 2 & Total & 1 & HFx 25 & 2 \\
\hline Total & 1 & SI_pos & 1 & HFx25 & 2 & power_25 & 1 & $\% \mathrm{HF} 25$ & 2 \\
\hline Power-25 & 1 & L1_pos & 1 & $\% \mathrm{HFx} 25$ & 2 & Total_pow & 1 & HFx25 & 2 \\
\hline Total_pow & 1 & Delta & 1 & HFx25 & 2 & HF_int_p & 1 & HVR-ind-p & 1 \\
\hline Delta_int_p & 1 & Teta & 1 & HVR-ind-p & 1 & HF_per_int_p & 1 & HVR-ind-n & 1 \\
\hline power int_p & 1 & $\%$ Alpha & 1 & HVR-ind-n & 1 & Delta_int_p & 1 & SI_p & 1 \\
\hline Total_int_p & 1 & $\%$ Beta & 1 & SI_p & 1 & powe5_int_p & 1 & L1_p & 1 \\
\hline & & Total & 1 & L1_p & 1 & Total_int_p & 1 & Delta & 1 \\
\hline & & Power-25 & 1 & SI_n & 1 & & & Teta & 1 \\
\hline & & Total_pow & 1 & L1_n & 1 & & & Total & 1 \\
\hline & & Delta_int_p & 1 & Delta & 1 & & & power25 & 1 \\
\hline & & power_25_int_p & 1 & Teta & 1 & & & Total_pow & 1 \\
\hline & & Total_int_p & 1 & Total & 1 & & & HF_int_p & 1 \\
\hline & & & & power_25 & 1 & & & HF_per_int_p & 1 \\
\hline & & & & Total_pow & 1 & & & Delta_int_p & 1 \\
\hline & & & & Delta_int_p & 1 & & & power 25 int_p & 1 \\
\hline & & & & power 25 int $p$ & 1 & & & Total_pow-int_p & 1 \\
\hline & & & & Total_nt_p & 1 & & & & \\
\hline від'ємні & $\mathrm{n}$ & & & від'ємні & $\mathrm{n}$ & від'ємні & $\mathrm{n}$ & від'ємні & $\mathrm{n}$ \\
\hline RR-neg-mean & 2 & & & $\%$ Delta & 3 & RR-n-mean & 2 & $\%$ Delta & 3 \\
\hline Delta & 1 & & & RR-n-mean & 2 & Delta & 1 & RR-neg-mean & 2 \\
\hline$\%$ Delta & 1 & & & $\% \mathrm{HF}$ & 1 & Total & 1 & $\% \mathrm{HF}$ & 1 \\
\hline$\%$ Alpha & 1 & & & Delta & 1 & & & Delta & 1 \\
\hline Total & 1 & & & $\%$ Alpha & 1 & & & $\%$ Alpha & 1 \\
\hline & & & & $\%$ Beta & 1 & & & $\%$ Beta & 1 \\
\hline & & & & $\% \mathrm{HF} 225$ & 1 & & & $\%$ HFx 25 & 1 \\
\hline & & & & Total & 1 & & & Total & 1 \\
\hline
\end{tabular}

Примітка. ДК/ВК - відношення додатних корелят до від'ємних корелят 
11. Частота та кількість корелят між показниками часового та спектрального аналізу.

12 Кореляційна особливість адаптації за фазою компресії плеча.

13. Яка складова спектру корелює 3 ширшим за діапазоном спектром (прикл. VLF (0,015-0,04 Гц)-Delta $(0-0,4$ Гц $)$.

14. Кількість, рівні та якості регуляторних механізмів, залучених в адаптацію (сумарний ефект регуляції, функція автоматизму, вегетативний баланс, стійкість регуляції, активність серцево-судинного підкоркового нервового центру).

Результати дослідження та їх обговорення. Для наочності запропоновано застосування цього алгоритму при аналізі адаптаційних механізмів при наступних патологічних станах та у здорових людей (показники АО та ЕКГ): здорові в положенні сидячи, ішемічна хвороба серця (IXC), атеросклероз (АС), артеріальна гіпертензія І ступеня (АГ-1), екстрасистолія (ЕС), гіпертонічна хвороба II стадії, кардіосклероз (КС), порушення ритму серця, постінфартний кардіосклероз (ПІКС), цукровий діабет (ЦД), стенокардія (СК), стенокардія напруги (CКН), порушення функції провідності серця, хронічне обструктивне захворювання легень (ХОЗЛ), шийний остеохондроз (ШОХ). В табл. 1 показано складові кореляційного портрету деяких станів (назви показників, частота їх появи, додатні та від'ємні кореляти). Розглядали кореляти, що знаходились в інтервалі від 0,9 до 1 та від -0,9 до -1 (значущі).

Саме для хворих на інфаркт міокарда виявили притаманний кореляційний зв'язок між триангулярним індексом та потужністю спектру хвиль другого порядку, що відображає участь вищих вегетативних центрів у загальній варіабельності серцевого ритму. Співвідношення кількості додатних і від'ємних корелят є найменшим для здорових і дорівнює 2,3 для АО і 2,1 для ЕКГ. Слід відмітити, що вказане співвідношення для ЕКГ зустрічається і для хворих з IXC та АГ І ступеня.

Для проведення побудови кореляційного портрету на основі аналізу біосигналів (АО, ЕКГ, електроенцефалограма, пульсограма, аудіограма) розроблено програмне середовище «OscEcgReoPuls».

Застосування запропонованих критеріїв побудови кореляційного портрету допоможе створити специфічну групу ознак для досліджуваного патологічного стану чи терапії.

Висновок. Побудова кореляційних портретів дозволяє доповнити існуючи методи диференцій- ної діагностики для більш якісного їх проведення та застосувати їх для оцінки ефективності терапії. Запропонований алгоритм допоможе глибше зрозуміти патоморфологічні механізми, задіяні при адаптації організму до різних патологічних станів. Вказаний підхід може бути використаний для побудови кореляційних портретів в медицині (за різних патологічних станів, реакцій на фізичне навантаження, лікувальних та діагностичних алгоритмів, у страховій медицині, діяльності лікувального закладу), в економіці (діяльність підприємства, курс валют), екології тощо.

\section{Література.}

1. Баевский Р. М. Оценка адаптационных возможностей организма и риск развития заболеваний / Р. М. Баевский, А. П. Берсенева.-М. : Медицина, 1997. — 256 с.

2. Вакуленко Д. В. Інформаційна система морфологічного, часового, частотного та кореляційного аналізу артеріальних осцилограм у фізичній реабілітації : монографія / Д. В. Вакуленко. - Тернопіль : ТДМУ, 2015. - $212 \mathrm{c}$.

3. David A. How slow is the k-means method? / D. Arthur, S. Vassilvitskii // Proceedings of the twenty-second annual symposium on computational geometry (SoCG), Sedona, Arizona, USA, June 05-07, 2006. — New York, USA: ACM Press, 2006. - P. 144.

4. Rodgers J. L. Thirteen ways to look at the correlation coefficient / J. L. Rodgers, W. A. Nicewander // The American Statistician. - 1988. - No. 42. - C. 59-66.

\section{References.}

1. Baevskii, R. M., Berseneva, A. P. (1997). Otsenka adaptatsionnykh vozmozhnostei organizma i risk razvitiya zabolevanii [Assessment of adaptive capabilities of the body and the risk of developing diseases]. Moscow: Meditsina [in Russian].

2. Vakulenko, D. V. (2015). Informatsiina sistema morfologichnogo, chasovogo, chastotnogo ta korelyatsiinogo analizu arterial'nikh ostsilogram $\mathrm{u}$ fizichnii reabilitatsii [Information system of morphological, temporal, spectral and correlation analysis of arterial oscillograms in physical rehabilitation]. Ternopyl: Ukrmedknyha. [in Ukrainian]. doi.org/10.13140/rg.2.1.2833.3684.

3. Arthur, D., \& Vassilvitskii, S. (2006). How slow is the k-means method? In Proceedings of the twenty-second annual symposium on Computational geometry SCG '06 (p. 144). New York, USA: ACM Press. doi. org/10.1145/1137856.1137880.

4. Rodgers, J. L., \& Nicewander, W. A. (1988). Thirteen ways to look at the correlation coefficient. The American Statistician, 42(1), 59. doi.org/10.2307/2685263. 